- Dentists are obliged to explain the risks associated with GA dental extractions to parents: this paper will help dentists to warn parents about post-operative morbidity.

- The preparation of children to facilitate coping strategies to enable them to accept anaesthetic induction is important but is less widely available for CDGA patients.

- This paper links dental anxiety to anaesthetic induction distress and so may alert dentists and CDGA service providers to those children who most need preparation eg play therapy pre-CDGA.

\title{
Dental anxiety, distress at induction and postoperative morbidity in children undergoing tooth extraction using general anaesthesia
}

\author{
M. T. Hosey, ${ }^{1}$ L. M. D. Macpherson, ${ }^{2}$ P. Adair ${ }^{3}$ C. Tochel, $_{1}^{4}$ G. Burnside ${ }^{5}$ and C. Pine ${ }^{6}$
}

\begin{abstract}
Objective To report on the prevalence of postoperative morbidity in children undergoing tooth extraction under chair dental general anaesthetic (CDGA) in relation to pre-operative dental anxiety and anaesthetic induction distress.
\end{abstract}

Design A prospective national study.

Setting Twenty-five Scottish DGA centres in 2001.

Subjects and method Four hundred and seven children (mean age 6.6 years; range: 2.3 to 14.8 years; $52 \%$ male). Before CDGA, the Modified Child Dental Anxiety (MCDAS) and Modified Dental Anxiety (MDAS) Scales were completed for children and accompanying adult respectively; the latter also returned a morbidity questionnaire 24 hours and one week post-operatively. Anaesthetic induction distress was scored immediately before CDGA induction using the Children's Hospital of Eastern Ontario Pain Scale (CHEOPS).

Results The mean MCDAS score was 24.2 (population norm 18.2); 21\% of adults were anxious. Forty-two per cent of children had induction distress; this related to their MCDAS scores ( $r=0.43, p<0.001$, Pearson Product Moment Correlation Coefficient). Morbidity at 24 hours and seven days was $63 \%$ and $24 \%$ respectively; this related to MCDAS scores $(r=0.15$, $p=0.029$ and $r=0.17, p=0.009$, Pearson Product Moment Correlation Coefficient) and to induction distress $\left(\mathrm{chi}^{2}=7.14, \mathrm{p}=0.007\right.$ and $\mathrm{chi}^{2}=11.70$, $\mathrm{p}=0.001$ ).

Conclusion The majority of children suffered next day morbidity and many still had symptoms a week later. Most children were dentally anxious; this related to induction distress and postoperative morbidity.

\footnotetext{
1*Senior Lecturer/Honorary Consultant in Paediatric Dentistry, University of Glasgow Dental School, 378 Sauchiehall Street, Glasgow, G2 3JZ; ${ }^{2}$ Senior Lecturer/Honorary Consultant in Dental Public Health, University of Glasgow Dental School, 378 Sauchiehall Street, Glasgow, G2 3JZ; ${ }^{3}$ Consultant Clinical Psychologist/Honorary Research Fellow (Liverpool Dental Hospital), Department of Clinical Psychology, 4th Floor, Bostock House, The Royal Hospitals, Grosvenor Road, Belfast BT12 6BA; ${ }^{4}$ Health Services Researcher, NHS Quality Improvement Scotland, 50 West Nile Street, Glasgow, G1 2NP; ${ }^{5}$ Clinical Dental Sciences, University of Liverpool; ${ }^{6}$ Professor of Dental Public Health and Primary Dental care, Liverpool University dental Hospital and School of Dentistry, Pembroke Place, Liverpool, L3 5PS

${ }^{*}$ Correspondence to: Marie-Therese Hosey

Email:m.t.hosey@dental.gla.ac.uk
}

Refereed paper

Accepted 10 Jan 05

doi: $10.1038 /$ sj.bdj.4813123

๑ British Dental Journal 2006; 200: 39-43
A high proportion of adult correspondents to a helpline for dental phobics reported that the trauma of childhood tooth extraction under a chair dental general anaesthetic (CDGA) was the initial source of their dental anxiety. ${ }^{1}$ While some of these respondents might already have been dentally anxious prior to CDGA referral, the induction of anaesthesia in particular is a stressful procedure for a child, due to separation anxiety, relative loss of control, sequencing of events or the unfamiliar environment and personnel. ${ }^{2}$ A child's dental fear is more strongly associated with the subjective experience of pain and trauma than with objective dental pathology ${ }^{3}$ and is influenced by parental, particularly maternal anxiety ${ }^{4-6}$ and is greatest in families with high caries levels. ${ }^{7,8}$

General anaesthesia facilitates operative dental treatment but does little to manage dental anxiety. Arch et al. ${ }^{9}$ comparing the level of postoperative anxiety in children undergoing CDGA extractions to those receiving local analgesia facilitated by nitrous oxide inhalation sedation, reported that the choice of inhalation sedation favoured reduced postoperative anxiety despite similar pre-operative anxiety levels. ${ }^{9}$

Nevertheless, for some children, CDGA is unavoidable. There are many reasons for referral: dental pain, facial swelling, extractions in multiple quadrants, the young age of the patient and a history of poor co-operation. ${ }^{10}$

While the number of general anaesthetics administered for dental treatment in the UK has reduced dramatically, Scotland continues to have the highest rate of CDGA in the world. Indeed, in Scotland, larger numbers of teeth are extracted rather than restored compared to demographically similar areas in Europe that have matching levels of decayed teeth in five and six year old children. ${ }^{11}$ A culture of dental extractions under CDGA has become established over many years, and accepted by Scottish families and dentists as the principal method of dental treatment of carious primary teeth, even though it is increasingly acknowledged to be a treatment of last resort. ${ }^{12}$

Cases of mortality following CDGA for children have been instrumental in UK reviews of service provision. Although deaths are rare, morbidity is commonplace. Bridgman et al. ${ }^{13}$ reported that for 80 children aged 2-15 years undergoing CDGA, 92\% complained of symptoms associated with the procedure. Twenty per cent were distressed at induction, 33\% were distressed during recovery, 39\% cried on the journey home and 37\% continued 


$\begin{aligned} & \text { Table } 1 \\
& \text { questionnaire }\end{aligned}$
\begin{tabular}{llll} 
Non-respondents versus respondents to postoperative morbidity \\
& $\begin{array}{l}\text { Non-Respondents } \\
\mathbf{N}=\mathbf{1 5 7}\end{array}$ & $\begin{array}{l}\text { Respondents } \\
\mathbf{N}=\mathbf{2 5 0}\end{array}$ & Significance \\
\hline Child Age & $6.5(2.3)$ & $6.6(2.3)$ & n.s. \\
\hline Child Gender & $53 \%$ male & $52 \%$ male & n.s. \\
\hline Child MCDAS & $24.2(8.4)$ & $24.2(8.4)$ & n.s. \\
\hline Parent & $13.2(6.7)$ & $11.8(6.1)$ & $p=.041$ \\
MDAS & & & \\
\hline
\end{tabular}

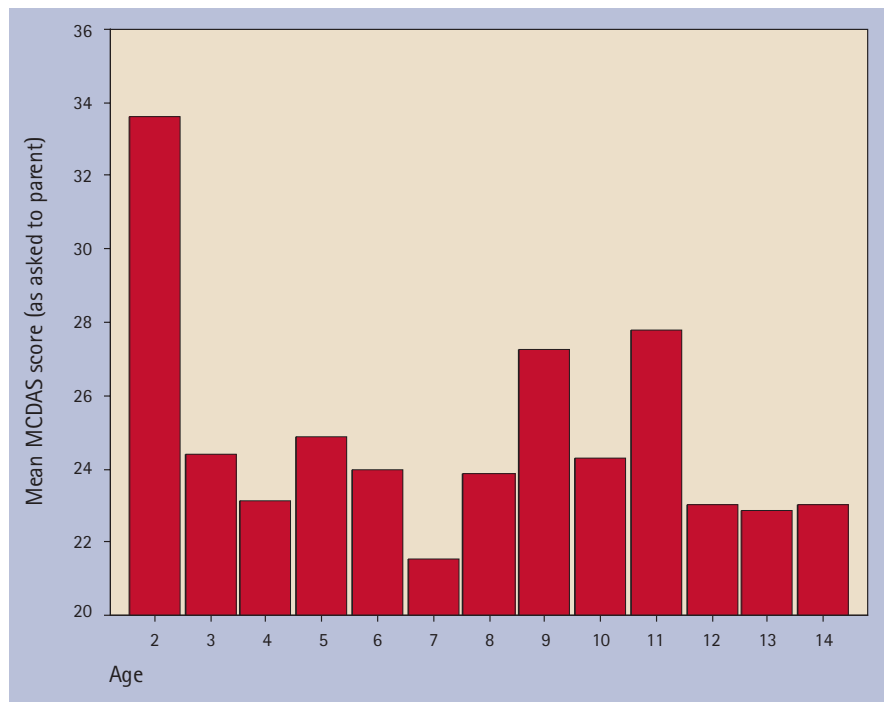

Fig. 1 MCDAS scores in relation to age of the child

crying at home. Other symptoms included nausea, sickness and prolonged bleeding.

Kain et al. (1999) reported that both parental and child anxiety could adversely influence postoperative problems such as nightmares, separation anxiety, eating disturbances and late onset enuresis. ${ }^{14}$ However, there is a scarcity of further evidence in the literature to support this, especially in relation to the effect of dental anxiety on anaesthetic induction distress, postoperative sequelae or the future parental acceptability of the CDGA procedure. Such information could assist referring dentists not only in both the clinical decision-making and informed consent process but also to better prepare children and parents for CDGA.

The aims of this study were: to study the level of dental anxiety in children and to evaluate the relationship between this and distress at induction and postoperative morbidity.

\section{METHOD}

Ethical approval was obtained from the Multi-Centre Research Ethics Committee for Scotland.

The data collection formed part of a national study of paediatric dental general anaesthetic services in Scotland. Twenty-five CDGA centres participated. The aim was to include all children up to age 16 years, referred for CDGA during two study weeks, the first in December 2000 and the second in March 2001. Informed consent was obtained from each participating child's parent or guardian, and from the child whenever appropriate.

Information was collected from 425 of the 480 children in 25 centres across Scotland who received a CDGA for dental extraction during the study periods. Patients for whom extractions were for reasons other than caries were excluded from this analysis, leaving 407 children in total. The mean age of participants was 6.6 years (range: 2.3 to 14.8 years; median 6.1 years) and 52\% were boys.

To measure anxiety pre-CDGA, The Modified Child Dental Anxiety Scale (MCDAS) ${ }^{15}$ was completed for all children by the accompanying parent. For children under eight years of age, this measure was only completed by a parent regarding their child's anxiety towards different aspects of dental visits, eg check-up, drill, and needle. The same questions were asked directly to those children eight years and over who completed the measure as a self-report tool. The minimum possible score using the MCDAS is ' 8 ' and the maximum is '40'. Parents/guardians also completed the Modified Dental Anxiety Scale (MDAS) regarding their own dental anxiety. ${ }^{16}$ The minimum possible score using the MDAS is ' 5 ' and the maximum is '25'. To assess anxiety at induction, nurses in the anaesthetic room were asked to note visible signs of distress immediately before CDGA induction using ratings from the Children's Hospital of Eastern Ontario Pain Scale (CHEOPS). ${ }^{17}$ This is a categorical scale, which includes signs such as crying, facial composure, obvious body tension and physical resistance to induction. When the responses in the categories are combined, children scoring greater than four are considered to have at least one visible symptom of distress.

Each accompanying adult was given a post-operative morbidity questionnaire and invited to complete the first section 24 hours after the CDGA. Parents were asked to report on seven factors including whether their child felt sick, vomited, had a sore mouth, had been unable to eat, had bad dreams, was drowsy or had a headache. Those children whose parents reported that their child had any of these features occurring 'more than usual' were classified as having postoperative symptoms. Parents were also asked to complete a second part of the questionnaire one week later in which four further questions were asked concerning whether their child: 1) became upset when someone mentioned doctors, dentists or hospitals; 2) was more attention-seeking; 3) had bad dreams at night or woke up crying; or 4) had a poor appetite. If parents reported any of these factors as occurring 'more than before' or 'much more than before', the child was deemed to have postoperative problems occurring one week later. The questionnaire also enquired about the parent's willingness for their child to undergo a future CDGA, using a 5-point scale, ranging from 'definitely yes' to 'definitely no'.

\section{RESULTS}

Data were received from 25 CDGA centres in Scotland and ranged from two patients (Perth Royal Infirmary, Caithness and Belford Hospitals) to 87 patients (Glasgow Dental Hospital \& School). The mean ages at each centre ranged from 4.2 years (Belford Hospital) to 10.6 years (Caithness).

When the child-reported anxiety scores were compared to the matched parent-reported child anxiety score, moderate agreement ${ }^{18}$ was found $(\mathrm{n}=100$, kappa $=0.45$,) and a significant correlation was seen $(0.68, \mathrm{p}<0.001$, Pearson Product Correlation Coefficient). Parent's rated their child's anxiety higher than the child rated themselves by a mean of 1.3 (range -16 to +17 , sd 6.09) on the MCDAS scale. Since the self-reporting MCDAS scores are only valid for children from eight years of age, only parent-reported child scores (using MCDAS) were used in the analysis to allow inclusion of the whole sample of child participants. A total of 347 anxiety questionnaires were returned complete, with the mean age of children being 6.7 years (median 6.2, range 2.3 to 14.8 years). The mean child dental anxiety level was 24.2 (CI: 23.3-25.1, range 8-40 in comparison to the population norm of 18.2. ${ }^{15}$ Child dental anxiety is detailed further in relation to the age of the children in Figure 1. With regard to the parent's own anxiety levels, the mean MDAS score was 12.4 (CI: 11.7-13.0, range 5-25), with 21\% having moderate to severe dental anxiety (a score greater than 18). ${ }^{16}$ There was no relationship between the child-reported MCDAS scores and parental dental anxiety (MDAS): $\mathrm{n}=99$ children with a mean age 9.0 years (sd 2.3, range 3.7-14.8); $r=0.09 p=0.353$, Pearson Product Moment Correlation Coefficient.)

A total of 400 CHEOPS forms were completed, (mean age 6.6 
years, median 6.1 years, range 2.3 to 14.8 years). Forty-two per cent of children had at least one visible sign of distress at CDGA induction. Considering only those children over the age of nine years, this figure was still relatively high (34\%) although there was a trend for older children to be less distressed (Fig. 2). A significant correlation was found between the CHEOPS and MCDAS scores (n $=340 ; \mathrm{r}=0.43 \mathrm{p}<0.001$, Pearson Product Moment Correlation Coefficient). Partialling out the influence of the effect of parental anxiety had no effect on this result. Those with a CHEOPS score of four or less ( $n=197$; 'no visible distress') had a mean MCDAS of 21.8 (CI: 20.7-22.8), while those with a CHEOPS score of five or above ( $\mathrm{n}=143$; 'at least one visible sign of distress') had a higher mean MCDAS score of 27.6 (CI: 26.2-29.1).

Following two mailings and telephone follow up, a total of $61 \%$ of all 407 participants' (71\% of the 347 who had complete anxiety questionnaires) parents completed the post-operative morbidity questionnaire. Non-respondent parents were significantly more dentally anxious than respondents; a more detailed comparison is shown in Table 1. Sixty-three per cent of the parents who responded reported that their children had experienced some problems in the subsequent 24 hours and 24\% one week later. The most common complaint at 24 hours was a 'sore mouth' and one week later $15 \%$ of respondents reported that their child was upset at the mention of doctors, dentists or hospitals, the complete results are detailed in Table 2. Two hundred and twenty-seven children (65\% of 347) had both child dental anxiety and postoperative morbidity questionnaires completed. To test for a correlation between dental anxiety and post-operative morbidity, we counted the number of next day symptoms (maximum $=7$ ) and the number of next week symptoms (maximum $=4)$. A significant but weak correlation was found between the (parent-reported) MCDAS scores and morbidity at both 24 hours $(r=0.15 p=0.029$, Pearson Product Moment Correlation Coefficient) and one week postoperatively $(\mathrm{r}=0.17 \mathrm{p}=$ 0.009, Pearson Product Moment Correlation Coefficient). Partialling out the influence of parental anxiety had no effect on this result. For those for whom both induction distress and post operative morbidity questionnaires were completed $(n=213), 75(57 \%)$ of the children with no reported problems at induction had next day morbidity, while for those with induction distress 62 (75\%) were affected, this difference was significant $(\mathrm{chi}=7.41 \mathrm{p}=0.007$, chi-square test). One week later (Table 3), 21 (16\%) of those with no reported problems at induction had reported post-operative morbidity, while the corresponding figure for those who did suffer induction distress was 30 (37\%), this finding was also significant (chi $=11.70 \mathrm{p}=0.001$, chi-square test).

Thirty-six per cent of parents reported that they would 'definitely' choose for their child to have a CDGA again (Table 4). The comparison between these parents and those who would not definitely opt for a future CDGA is shown in Table 5.

\section{DISCUSSION}

This study has demonstrated a relationship between preoperative dental anxiety and both anaesthetic induction distress and reported postoperative morbidity.

Eighty-eight per cent of children who received a general anaesthetic for dental extractions in Scotland, during the two study weeks, participated in this study. The participating CDGA centres encompassed both rural and suburban areas across Scotland. Only data from children who required dental extraction due to caries were used, i.e. the relatively low number referred for orthodontic extractions or as a result of dental trauma were excluded. Local centres were asked to provide assistance for the data collection, supported and calibrated by the research assistant (CT). Despite this, not all of the questionnaires were returned complete, most notably the anxiety questionnaires. This is probably due to the added pressure of data collection during a busy general anaesthetic service. A contemporaneous study of anaesthetic practice for CDGA services reported that the majority of children underwent a gas induction, most commonly with servofluorane. Relatively few services offered intravenous induction, although of those who did, only half used topical anaesthesia prior to gaining intravenous access. ${ }^{19}$ The details relating to assessment for CDGA and the time lag between this and the CDGA visit have been previously reported in this population as part of the same project. ${ }^{20}$ The largest centre does undertake gaseous induction and the children are prepared immediately prior to this by nurses in a separate play area. However, clearly the waiting times and the method of preparation prior to anaesthetic induction will influence the child's anxiety and warrants further research. While the influence of the different centres and settings on the behaviour of the child at induction has to be acknowledged, the observers at

Table 2 Parental reported child morbidity in the 24 hours following CDGA, $\mathbf{n}=\mathbf{2 5 0}$. 'In the 24 hours since your child had his/her teeth taken out, how much was your child bothered by:...'

\begin{tabular}{|c|c|c|c|c|c|}
\hline & More than usual & Same as usual & Less than usual & Not at all & Total response \\
\hline Feeling sick & $38(16 \%)$ & $26(11 \%)$ & $2(1 \%)$ & $177(73 \%)$ & 243 \\
\hline Vomiting & $12(5 \%)$ & $29(12 \%)$ & $1(0 \%)$ & $197(82 \%)$ & 239 \\
\hline Unable to eat & $76(31 \%)$ & $46(19 \%)$ & $38(15 \%)$ & $86(35 \%)$ & 246 \\
\hline $\begin{array}{l}\text { Bad dreams / } \\
\text { unable to sleep }\end{array}$ & $17(7 \%)$ & $48(20 \%)$ & $3(1 \%)$ & $175(72 \%)$ & 243 \\
\hline Headache & $18(7 \%)$ & $25(10 \%)$ & $5(2 \%)$ & $195(80 \%)$ & 243 \\
\hline
\end{tabular}

Table 3 Parental reported child morbidity one week after CDGA, $n=250$

\begin{tabular}{|c|c|c|c|c|c|c|c|}
\hline & $\begin{array}{l}\text { Much less } \\
\text { than before }\end{array}$ & $\begin{array}{l}\text { Less than } \\
\text { before }\end{array}$ & $\begin{array}{l}\text { Same as } \\
\text { before }\end{array}$ & $\begin{array}{l}\text { More than } \\
\text { before }\end{array}$ & $\begin{array}{l}\text { Much more } \\
\text { than before }\end{array}$ & $\begin{array}{l}\text { Does not } \\
\text { apply }\end{array}$ & Total response \\
\hline $\begin{array}{l}\text { Upset at mention } \\
\text { of doctors, dentists, } \\
\text { hospitals }\end{array}$ & $7(3 \%)$ & $12(5 \%)$ & $162(66 \%)$ & $31(13 \%)$ & $5(2 \%)$ & $29(12 \%)$ & 246 \\
\hline $\begin{array}{l}\text { Spends time trying } \\
\text { to get hold of your } \\
\text { attention }\end{array}$ & $4(2 \%)$ & $3(1 \%)$ & 193 (78\%) & $19(8 \%)$ & $2(1 \%)$ & $25(10 \%)$ & 246 \\
\hline $\begin{array}{l}\text { Have bad dreams } \\
\text { or wake up crying }\end{array}$ & $7(3 \%)$ & $6(3 \%)$ & $170(71 \%)$ & $12(5 \%)$ & $3(1 \%)$ & $42(18 \%)$ & 240 \\
\hline Has poor appetite & $6(2 \%)$ & $7(3 \%)$ & $182(75 \%)$ & $14(6 \%)$ & $3(1 \%)$ & $31(13 \%)$ & 243 \\
\hline
\end{tabular}




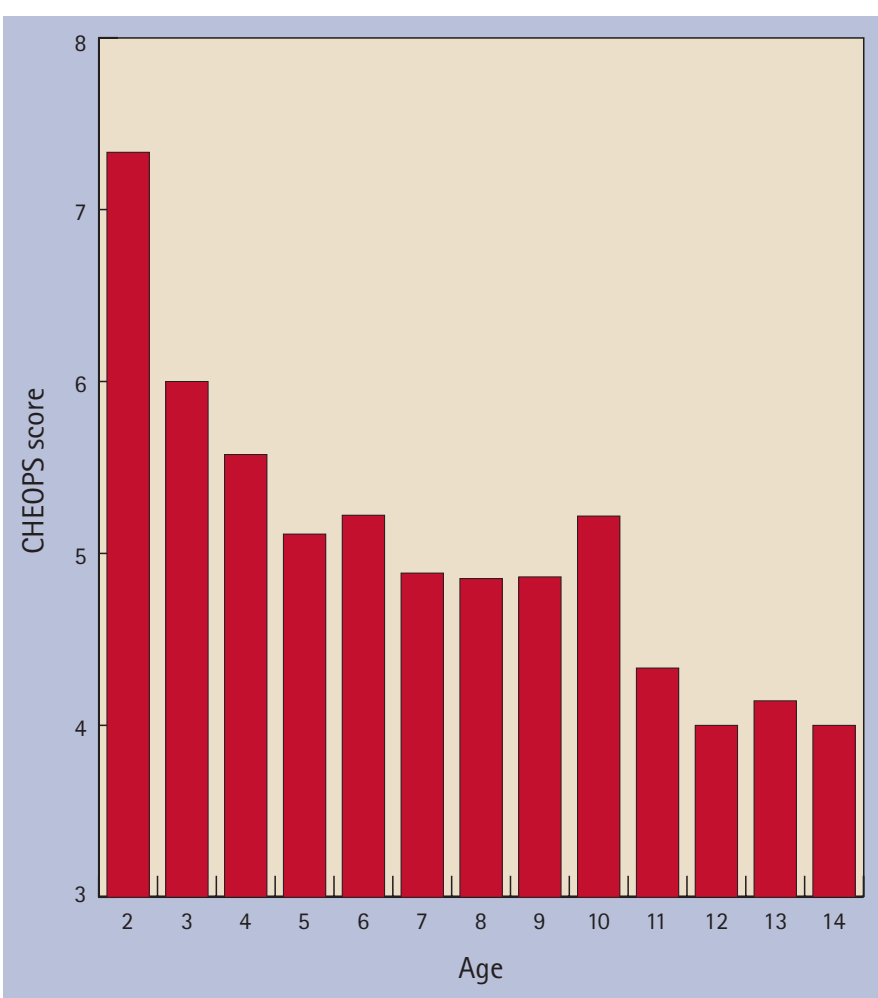

Fig. 2 CHEOPS scores in relation to age of the child at induction of CDGA

\begin{tabular}{|c|c|c|c|c|c|}
\hline \multicolumn{6}{|c|}{ Scale } \\
\hline $\begin{array}{l}1 \\
\text { 'Definitely } \\
\text { yes' }\end{array}$ & 2 & 3 & 4 & $\begin{array}{l}5 \\
\text { 'Definitely } \\
\text { no' }\end{array}$ & $\begin{array}{l}\text { Total } \\
\text { response }\end{array}$ \\
\hline $89(36 \%)$ & $51(21 \%)$ & $50(20 \%)$ & $26(11 \%)$ & $29(12 \%)$ & 245 \\
\hline
\end{tabular}

\begin{tabular}{|c|c|c|c|}
\hline & $\begin{array}{l}\text { Would } \\
\text { definitely } \\
\text { select GA }\end{array}$ & $\begin{array}{l}\text { Would not } \\
\text { definitely } \\
\text { select GA }\end{array}$ & significance \\
\hline Child's MCDAS & $22.1(8.4)$ & $25.3(8.3)$ & $\mathrm{p}=.007$ (t-test) \\
\hline Child's Age & $7.0(2.3)$ & $6.5(2.3)$ & n.s. \\
\hline Child's Gender & $51 \%$ Male & $54 \%$ Male & n.s. \\
\hline $\begin{array}{l}\text { Parent } \\
\text { MDAS }\end{array}$ & $12.3(6.4)$ & $11.7(5.9)$ & n.s. \\
\hline CHEOPS & $26 \%$ CHEOPS $>4$ & $47 \%$ CHEOPS $>4$ & $p=.001$ (chi-square) \\
\hline $\begin{array}{l}\text { Post-op } \\
\text { next day }\end{array}$ & $49 \%$ problems & $70 \%$ problems & $p=.001$ (chi-square) \\
\hline $\begin{array}{l}\text { Post-op } \\
\text { next week }\end{array}$ & $11 \%$ problems & $31 \%$ problems & $p=.001$ (chi-square) \\
\hline
\end{tabular}

induction used a relatively simple scale (CHEOPS) and had previously been calibrated in its use. Furthermore, even when it was simplified to 'distress' and 'no distress' the association with both dental anxiety and postoperative morbidity was still clear.

Nevertheless, the finding that children referred for CDGA are more dentally anxious than their peers, confirms previous studies. $^{21,22}$ In six-year-old children, dental anxiety status has been found to be associated with irregular dental attendance and a history of previous disruptive behaviour in the dental setting, as well as to general psychological developmental factors such as: food fads, disturbed sleep, separation anxiety, poor bowel or bladder control, increased sibling rivalry and fearfulness of everyday objects. A complex interaction exists where the role of the mother plays a central part in both the child's degree of psychological development and the child's ability to cope. ${ }^{23}$

A limitation of the present study was the use of the parentreported MCDAS since, even though the correlation between the parent reported and child reported scores was high, the agreement was moderate. This was due to the parent rating the child's anxiety higher than the child rated themselves, probably attributable to their own greater knowledge and anticipation of what was to follow. Despite this, it was assumed that the same strong correlation could be extrapolated to the younger children in the sample. Therefore, the comparison of the mean parent-reported MCDAS scores in this study with the population norms in the child-reported MCDAS by Wong et al. (1998) ${ }^{15}$ should be considered with a degree of caution. The accurate measurement of child anxiety is challenging, especially in young children. Carson and Freeman (1997) validated clinical observations by the dentist and dental nurse as a method of assessing a child's dental anxiety status at routine dental examination. ${ }^{24}$

Before that, Hosey and Blinkhorn (1995) evaluated different scales based on clinical observation of anxiety in children facilitated by video recording during conscious sedation visits. ${ }^{25}$ However, the children in the present study were younger than those in either of these studies. Moreover, the multi centre design of the present study and the fact that data collection occurred in these different settings at the visit for tooth extraction under general anaesthesia which is usually a busy time - precluded the accurate use of clinical observation to score pre-operative anxiety. The use of parental reporting of child anxiety is common. Indeed, it has been reported that parents, especially mothers, can be relied upon to make an objective assessment of their child's anxiety, ${ }^{26}$ especially in the CDGA situation. ${ }^{22}$ Nevertheless, the parent's own anxiety level might bias them against accurately reporting the anxiety of their child. However, while maternal anxiety has long been accepted in the aetiology of child dental anxiety, ${ }^{4,5}$ this does not necessarily mean that this link would lead to reporting bias. Indeed, in a similar study undertaken in the CDGA environment, Balmer et al. ${ }^{22}$ also found no relationship between the anxiety of the child and that of the accompanying parent. Moreover, while Carson et al. ${ }^{21}$ reported an association between the child's self report of dental anxiety and the parental perception of the child's anxiety, there was no link between parental dental anxiety and the child's self-reported dental anxiety. In the present study, statistically correcting for any influence in the report of child anxiety due to the parent's own anxiety level was found to make no difference to the results.

The mean parental MDAS score in the present study is 12.4 ; this is higher than previously reported in mothers attending with their children for routine dental check-ups (10.36) but less than that found in adult females (12.87). ${ }^{16}$ Carson and Freeman ${ }^{21}$ reported that the parents of children referred for CDGA were more anxious than those whose children undergo either routine dental care or inhalation sedation, although these data were collected at the assessment stage rather than at the time of the CDGA visit. ${ }^{21}$ Parental anxiety is highest at the time of the CDGA visit, ${ }^{22}$ and peaks after anaesthetic induction. ${ }^{27}$ In the present study, the level of parental anxiety was measured immediately before and during the CDGA visit and so the levels were expected to have been higher.

The CHEOPS score demonstrated a high prevalence of visible distress in the children at induction of anaesthesia, particularly but not exclusively in the pre-schoolers. This was so strongly linked to the child's level of dental anxiety that the parent-reported MCDAS might prove beneficial as a predictor of child distress at CDGA induction. It is noteworthy that while those children who had no sign of distress at induction had a MCDAS score above the population norm, their mean score was still less than the mean score of the sample as a whole, lending further credence to the association between dental anxiety and induction distress. Schwartz et al. ${ }^{2}$ 
showed that play therapy sessions, coupled with rehearsal, can reduce anxiety and help young children cope with induction of anaesthesia more effectively. Preoperative therapy is widely available to children referred for both non-dental general anaesthetic induction and for children undergoing more comprehensive (restorative) dental treatment in specialist paediatric units. Targeting preparatory schemes towards the most dentally anxious children may be a cost-effective beginning to its wider development within CDGA services.

The levels of nausea and drowsiness recorded in the present study were similar to those of Bridgeman et al. ${ }^{13}$ while the prevalence of 'sore mouth' and 'problems with eating' were higher and 'vomiting' was lower. The present study also found much higher levels of induction distress. Few researchers have examined the relationship between pre-operative anxiety and the postoperative clinical recovery. ${ }^{14}$ This study has found a significant relationship between reported morbidity and both pre-operative parent-reported child dental anxiety and anaesthetic induction distress. This suggests that the most dentally anxious child is more likely to be upset at induction and to suffer, or their parent is more likely to report, adverse sequelae. Although, in respect to the latter, it is noteworthy that it was the most anxious parents who were the poorest respondents.

The willingness to select CDGA for future treatment was lower in parents of the most dentally anxious children and among those whose child had exhibited either distress at induction or postoperative morbidity. Despite this, over half of parents intimated that they were likely to opt to have CDGA again. This is perhaps predictable given the culture of acceptability and reliance on CDGA in Scotland. It is hoped that these children, once treated, remain caries-free but previous research has shown that between 23\% and $31 \%$ of them will need further CDGA dental extractions, with those below four years of age having the highest risk. This may be due to the failure to treat all the dental disease or establish appropriate preventive therapy following the first visit. ${ }^{10,28}$ Nevertheless, for children who require CDGA there is a need to develop means by which they can be helped to cope better with what they are likely to remember as a distressing experience.

\section{CONCLUSION}

The majority of children undergoing CDGA are dentally anxious. Dental anxiety, induction distress and postoperative morbidity are interrelated.

Supported by CRAG, Scottish Health Department, Project No. 99/42.

The authors are most grateful to, and would like to thank all the nurses, anaesthetists, dentists and other staff members in the CDGA centres that took part in this study.

1. Hosey M T, Robertson I, Bedi R. A review of correspondence to a general dental practice 'Helpline' service. Prim Dent Care 1995; 2: 43-46.
2. Schwartz $B H$, Albino $J E$, Tedesco $L$ A. Effects of psychological preparation on children hospitalised for dental operations. J Ped 1983; 102: 634-638.

3. Townend E, Dimigen G, Fung D. A clinical study of child dental anxiety. Behaviour Research and Therapy 2000; 38: 31-46.

4. Johnson R, Baldwin D C. Maternal anxiety and child behaviour. J Dent Child 1969; 36: 87-92.

5. Bailey P M, Talbot A, Taylor P P. A comparison of maternal anxiety levels with anxiety levels manifested in the child dental patient. J Dent Child 1973; 40: 277-284

6. Klingberg G, Berggren U. Dental Problem behaviours in children of parents with severe dental fear. Swed Dent J 1992; 16: 27-32.

7. Bedi R, Sutcliffe P, Donnan P, Barrett N, McConnachie J. Dental caries experience and prevalence of children afraid of dental treatment. Comm Dent Oral Epid 1992; 20: 368-371.

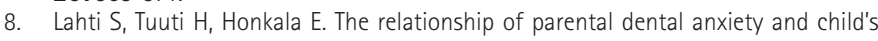
caries status. J Dent Child 1989; 56: 191-195.

9. Arch L M, Humphris G M, Lee G TR. Children choosing between general anaesthesia or inhalation sedation for dental extractions: the effect on dental anxiety. Int $J$ Paed Dent 2000; 11: 41-48.

10. MacCormac $C$, Kinirons M. Reasons for referral of children to a general anaesthetic service in Northern Ireland. Int J Paed Dent 1998: 8: 191-196.

11. Bolin A K. Children's dental health in Europe. An epidemiological investigation of 5- and 12-year old children in eight EU countries. Swed Dent J 1997; 122: 1-88.

12. British Society of Paediatric Dentistry. A policy document on oral health care in preschool children. Int J Paed Dent 2003; 13: 279-285.

13. Bridgman $C M$, Ashby $D$, Holloway $P J$. An investigation of the effects on children of tooth extraction under general anaesthesia in general dental practice. Br Dent J 1999; 186: $245-247$

14. Kain Z N. Perioperative information and parental anxiety: the next generation (Editorials). Anesthesia and Analgesia 1999; 88: 237-239.

15. Wong $\mathrm{H}$ M, Humphris $\mathrm{G}$, Lee $\mathrm{G}$. Preliminary validation and reliability of the modified child dental anxiety scale. Psychological Reports 1998; 83: 1179-1186.

16. Humphris M, Morrison T, Lindsay S J E. The Modified Dental Anxiety Scale: validation and United Kingdom norms. Comm Dent Health 1995: 12: 143-150.

17. McGrath P J, Johnson G, Goodman J T et al. CHEOPS: A behavioral scale for rating postoperative pain in children. In Advances in pain research and therapy. Vol 9. Raven Press, 1985.

18. Landis J R, Koch, G G. The measurement of observer agreement for categorical data. Biometrics 1977; 33: 159-174

19. Macmillan C S A, Wildsmith J A W. A survey of paediatric anaesthesia in Scotland. Anaesthesia 2000; 55: 581-596.

20. Tochel C, Hosey M-T, Macpherson L, Pine C. Assessment of children prior to dental extractions under general anaesthesia in Scotland. Br Dent J 2004; 196: 629-633.

21. Carson $P_{1}$ Freeman R. Dental caries, age and anxiety: factors influencing sedation choice for children attending for emergency dental care. Comm Dent Oral Epid 2001 29: 30-36.

22. Balmer R, O'Sullivan E A, Pollard M A, Curzon M EJ. Anxiety related to dental general anesthesia: changes in anxiety in children and their parents. Euro J Paed Dent 2004; 5: 9-14.

23. Corkey B, Freeman R. Predictors of dental anxiety in six-year-old children: Findings from a pilot study. J Dent Child 1994; 61:267-271.

24. Carson P, Freeman R. Assessing child dental anxiety: the validity of clinical observations. Int J Paed Dent 1997: 7: 171-176

25. Hosey M T, Blinkhorn A S. An evaluation of four methods of assessing the behaviour of anxious child dental patients. Int J Paed Dent 1995; 5: 87-95.

26. Foylan $\mathrm{M} \mathrm{O}$, Idehen $\mathrm{E} \mathrm{E}_{1}$ Ojo $0 \mathrm{O}$. Dental anxiety in a subpopulation of African children: parent's ability to predict and its relation to general anxiety and behaviour in the dental chair. Euro J Paed Dent 2004; 5: 19-23.

27. Goldvasser $Y$, Julliard K. Parental anxiety levels during pediatric induction with and without administration of premedication for general anesthesia. J Clin Ped Dent 2003; 28: 85-88.

28. Harrison M, Nutting L. Repeat general anaesthesia for paediatric dentistry. Br Dent J 2000; 189: 37-39. 